Pensamiento Crítico Vol. 19 № 1, pp. 135-148

\title{
Algunas notas sobre los objetivos de la devaluación
}

Some notes on the objectives of the devaluation

Econ. Pablo Rivas Santos*

\section{RESUMEN}

El presente artículo analiza los fundamentos teóricos de los objetivos de la devaluación suponiendo que el patrón monetario "moneda libremente oscilante" es un instrumento ideado para provocar inflación. Este patron monetario se implantó para evitar dificultades técnicas a los BCR en su actividad inflacionaria.

La historia económica ha demostrado que las instituciones sindicales, políticas y estatales (durante épocas de euforia alcista) al lograr implantar salarios superiores a los salarios que el mercado de trabajo hubiera implantado, provoca desempleo institucional (no obstante la continua expansión del crédito). Pero la cosa se agrava cuando, finalmente, se produce la inevitable recesión y comienzan a subir los precios. Esas instituciones rechazan toda rebaja de los salarios nominales, por lo que tal desempleo aumentará (incidentalmente aquellos trabajadores que, pese a todo, continúan trabajando, verán incrementados sus salarios nominales). Los millones de desempleados constituyen una seria amenaza para la paz interna. Ante una situación llena de peligros, los Gobiernos acuden a la devaluación. Ya que esas

* Economista y egresado de la maestría en finanzas por la Universidad Nacional del Callao. Profesor auxiliar de la FCE - UNMSM. Miembro del Instituto de Investigaciones Económicas FCE - UNMSM. 


\section{Pensamiento Crítico Vol. 19. N I}

instituciones rechazan que se reajusten esos salarios coactivamente fijados al valor de la moneda y al nivel de precios, lo que procede, según ellos, es reajustar el valor de la moneda y el nivel de los precios a esos salarios coactivamente fijados. No es que esos salarios coactivamente fijados sean demasiado altos; lo que sucede es que la moneda nacional está sobrevaluada con respecto a las monedas extranjeras por lo que se debe proceder a reajustar esta última relación. La devaluación será el remedio.

Palabras clave: instituciones, desempleo institucional, devaluación, precios, salarios

\section{ABSTRACT}

This paper analyzes the theoretical foundations of the objectives of devaluation assuming the pattern Monetary Currency Freely Swinging is a tool designed to cause inflation. Was introduced to avoid the technical difficulties in its inflationary activity BCRs.

Economic history has shown that the Trade Unions, State Policies and Institutions (during times of bullish euphoria) to achieve higher wages to implement wage labor market have implemented institutional cause unemployment (despite the continued expansion of credit). But things get worse when, finally, the inevitable downturn occurs and begin to raise prices. These institutions reject any cuts in nominal wages so that unemployment will rise. (Incidentally those workers who, despite everything, still working, will see increases in their nominal wages ). The millions of unemployed constitute serious threat to internal peace. Faced with a situation fraught with danger, governments come to depreciation. Since these institutions reject those coercively fixed wages are adjusted to the value of money and the price level; what they believe is appropriate to adjust the value of the currency and price levels to those coercively fixed wages. No coercion is that these wages are set too high; what happens is that the currency is overvalued relative to foreign currencies and, therefore, proceed to adjust the latter relationship. The depreciation will be the remedy.

Keywords: Institutions, institutional unemployment, devaluation, prices, wages. 


\section{Pablo Rivas Santos}

\section{Introducción}

Los objetivos que se persiguen con la devaluación son: mantener los salarios nominales e incluso aumentarlos (mientras los salarios reales se reducen), incrementar (en moneda nacional) los precios de los productos nacionales, favorecer a los deudores a costa de los acreedores y fomentar las exportaciones y reducir las importaciones.

Pero ni los Gobiernos ni los economistas (que defienden la devaluación) se atreven a decir que, lo que se pretende con la devaluación es reducir los salarios reales. Prefieren decir que la devaluación tiene como objetivo combatir un supuesto desequilibrio estructural entre el nivel de precios nacionales y el nivel de precios internacionales. Reconocen que es necesario reducir los costos nacionales de producción, pero cuidadosamente no hablan de que uno de esos costos que piensan reducir son los salarios reales y que el otro costo es lo pagado por los intereses y principal de los préstamos (de mediano y largo plazo).

Los Gobiernos capitulan ante esas instituciones y, por salvar su prestigio, se resisten a admitir que la política salarial que alaban ha fracasado, provocando desempleo permanente. La devaluación es un recurso desesperado al que acuden esos Gobiernos débiles, pero deseosos de mantenerse en el poder a toda costa. Gustosos pasan por alto las contradicciones del sistema, pues les permiten prolongar su mandato. A los exportadores les dicen que la devaluación mejoraría los precios. En cambio, a los consumidores les promete evitar toda alza del costo de vida mediante el cumplimiento de la meta de inflación, en una banda entre 3\% y $5 \%$.

Esos Gobiernos pueden justificar su conducta alegando que la gente (influenciada por falsas ideologías de esas instituciones) los presionaba, haciendo imposible cualquier otra alternativa. En cambio, a tal justificación no pueden apelar cuantos economistas han defendido ese patrón monetario. Porque mientras esos Gobiernos no ocultan que la devaluación había sido dictada por razones de emergencia y que no volvería a emplearse. Esos economistas, en un afán por complacer a esos gobiernos y a los poderosos grupos de presión (montados por los empresarios mercantilistas), han exagerado al máximo las aparentes ventajas de ese patrón monetario. Pero las perniciosas consecuencias de tal sistema monetario pronto han aflorado, desvaneciéndose el inicial entusiasmo por las devaluaciones. 


\section{Pensamiento Crítico Vol. I9. No I}

\section{Conceptos fundamentales sobre los que se basa los objetivos de la devaluación}

Cuando se contempla la devaluación bajo el ojo del economista, es fácil darse cuenta de que todas esas pretendidas ventajas de ese patrón monetario son (en el mejor de los casos) solo temporales. Además, aquella tan elogiada bonanza del comercio exterior, solo se consigue cuando es un solo país quien devalúa. Si los restantes países devalúan en igual grado, el saldo del comercio exterior se mantiene inalterado. Y si esos restantes países devalúan en mayor grado, son esos restantes países quienes cosechan esas temporales ventajas. Por su parte, generalizadas las devaluaciones, se establecería un pugilato monetario que acabaría perjudicando al sistema monetario mundial.

Aquellas alabadas ventajas que parece reportar la devaluación (en materia de comercio exterior) aparecen porque el reajuste de precios y salarios nacionales a la nueva situación (provocada por la devaluación) exige cierto período de tiempo. Mientras tal proceso de adaptación no se completa, resulta favorecida la exportación y penalizada la importación. Sin embargo, este temporal efecto es consecuencia de que (a causa de la devaluación) la gente obtiene ahora menos por lo que exportan y pagan más por lo que importan; el consumo nacional se reduce. Aquellas personas en cuya opinión el saldo de la balanza de pagos con el exterior determina la riqueza del país serán las únicas personas que pudieran considerar favorable (para el bienestar de la gente) esa reducción del consumo nacional. El empresario, tras la devaluación, para importar una misma cantidad de insumos tiene que exportar una mayor cantidad de productos que antes.

La devaluación opera en beneficio de los deudores y en perjuicio de los acreedores. Pero con esa reducción de la carga de los deudores, quienes más se benefician son los grandes empresarios, que obtienen facilidades crediticias con los fondos aportados por la gente que invierte sus ahorros en valores de renta fija, préstamos hipotecarios, depósitos bancarios y seguros.

Aparte está el problema de los préstamos extranjeros. Cuando los países acreedores devalúan sus monedas, hacen pura donación a sus deudores extranjeros.

Se argumenta también a favor de ese patrón monetario, el que su implantación permite rebajar la tasa de interés dentro del país. El BCR bajo ese patrón monetario fija 


\section{Pablo Rivas Santos}

la tasa de interés nacional que le resulte más conveniente (no acomoda la tasa de interés nacional a las condiciones del mercado monetario internacional).

Este argumento no tiene sentido con respecto a países deudores (países que obtienen más créditos del extranjero). Cuando los países deudores implantan políticas monetarias sanas y estables sus ciudadanos, a partir de ese momento, con facilidad pueden obtener préstamos extranjeros en su propia moneda. Sin embargo, tales facilidades se desvanecen en cuanto varían esas políticas monetarias. Así, en lo relacionado a los créditos extranjeros, ninguna ventaja reporta esa devaluación. Y en lo relacionado a los créditos internos, la devaluación solo favorece a los deudores que obtuvieron sus créditos con anterioridad a esa devaluación, ya que la devaluación provoca una tendencia al alza del interés de mercado al incluir en este interés la positiva compensación por la posible futura subida de precios.

Esto último es aplicable al caso de los países acreedores en el mercado crediticio internacional. La tasa de interés no es un fenómeno monetario, por lo que la tasa del interés nunca puede ser (a la larga) influenciada por medidas monetarias.

La devaluación reduce los salarios reales y, por ende, es un paliativo para el alto desempleo entonces existente. El heterodoxo, quizá al afirmar que la devaluación fue un éxito al evitar que se lanzaran a la subversión las enormes masas de desempleados forzosos, tal vez quiera destacar que (dadas las corrientes ideológicas imperantes) ninguna otra fórmula permitía enfrentar mejor la situación. Sin embargo, el heterodoxo habrá de añadir que no se suprimió (por tales cauces) la causa de aquel tremendo desempleo institucional. La devaluación fue hábil maniobra que momentáneamente permitió eludir la irresponsabilidad de esas instituciones. Funcionó porque no menoscababa el prestigio de la dirigencia sindical. Pero precisamente porque dejaba intacta esa doctrina, solo por poco tiempo fue eficaz. Esas instituciones pronto aprendieron a distinguir entre salarios nominales y salarios reales. No se conforman con la simple subida de los salarios nominales. Ya no es posible engañar a la gente a base de reducir el poder adquisitivo del dinero. Por eso, la devaluación ha perdido su eficacia en el sistema laboral.

La heterodoxia (apelando a la artificiosa terminología de la economía matemática) se limitó a dar elegancia a la tesis de quienes habían defendido la inflación y la expansión del crédito. La heterodoxia ya no sabía cómo presentar sus recomendaciones de gastar sin freno; se reconocía incapaz de combatir con éxito el teorema relacionado 


\section{Pensamiento Crítico Vol. 19. N I}

al desempleo institucional. Los Gobiernos no tenían más remedio que lanzarse a la devaluación, a la inflación, a la expansión del crédito, al desequilibrio presupuestario y al gasto sin freno. Los gobiernos no pueden evitar la presión de la gente, no pueden ir contra aquellas ideologías que merecen credibilidad por falaces que sean. Les cabía dimitir, en vez de alabar políticas tan desastrosas para el país. Y menos excusa tienen los economistas que pretendieron justificar el más torpe de los errores : la inflación.

\section{Algunos conceptos fundamentales sobre los que se basó la expansión del crédito entre 2009-2013}

Por historia económica sabemos que los banqueros inventaron la expansión del crédito con el fin de intervenir la actividad de mercado. El dinero fiduciario fue un invento de los banqueros orientado a elevar los precios y salarios nominales, a bajar el interés y a reducir las deudas. El dinero fiduciario fue un invento de los banqueros, quienes al ver que su dinero bancario ( por las cantidades depositadas a la vista ) era usado como sustituto monetario, se lanzaron a prestar a terceros una parte de los fondos que tenían en custodia, buscando el correspondiente beneficio. No creían que encerraba peligro el no mantener en sus cajas el importe total de los resguardos de depósito emitidos por ellos mismos. Estaban convencidos de que nunca les faltaría el dinero líquido necesario para atender sus obligaciones y poder redimir a la vista el dinero bancario que les fuera presentado. La propia mecánica del mercado transformó el dinero bancario en dinero fiduciario.

Sin embargo, hoy en día corresponde al Estado, a través del BCR la responsabilidad de toda expansión del crédito. La intervención que tiene los bancos privados en las aventuras expansivas estatales es técnica y de colaboración. El BCR regula toda la actividad bancaria. El BCR determina el monto y las circunstancias de todas las operaciones crediticias. Mientras la banca privada ( bajo el signo del mercado ) tiene rigurosamente restringida su capacidad expansiva, el BCR provoca una continua y grave expansión del crédito. Esa expansión crediticia le permite aparentemente evitar la escasez de capital y reducir el interés. A su amparo financian ( con la máxima abundancia ) el gasto público, alimentan euforias alcistas aparentemente inacabables y hacen próspero a todo el mundo. 


\section{Pablo Rivas Santos}

Los efectos de la expansión crediticia son los efectos que prevé la teoría del ciclo económico ( la teoría monetaria de las fluctuaciones cíclicas ). El movimiento alcista es el efecto de previa expansión crediticia. Sin este movimiento alcista, la euforia no se mantendría ; en cuanto se frene el avance de la expansión crediticia, automáticamente, surgirá la depresión. Los heterodoxos en sus estudios sobre el ciclo económico, lo más que se atreven a afirmar es que la expansión crediticia no es la causa inicial del movimiento alcista, sino que son otros los factores que desencadenan ese movimiento alcista. Según reconocen, la expansión crediticia ( requisito de la euforia alcista ) no es provocada ( a sabiendas ) para rebajar el interés o para efectuar inversiones de momento improcedentes, dada la insuficiencia del capital disponible. Dicen que el fenómeno se origina si en la coyuntura concurren otros factores sin intervención del BCR.

Los heterodoxos se contradicen cuando se oponen a cualquier medida orientada a evitar la crisis : evitar la expansión crediticia. Los heterodoxos son lógicos cuando de su ideario ( falaz y contradictorio ) infieren que la expansión crediticia constituye el remedio económico. En cambio, aquellos economistas que reconocen que, sin la expansión crediticia, la euforia alcista sería imposible contradicen sus propias teorías cuando combaten las medidas orientadas a frenar la expansión crediticia. Los voceros estatales y los representantes de los poderosos grupos de presión ( al igual que los defensores de la economía heterodoxa ) proclaman que para evitar la crisis es necesario no provocar auges alcistas. No saben cómo replicar a los economistas que propugnan medidas que impiden la expansión crediticia. Y, sin embargo, se niegan tenazmente a escuchar cualquier sugerencia en tal sentido. Formulan censuras contra quienes se oponen a la expansión crediticia, acusándoles de querer perpetuar la depresión. Tal actitud pone de manifiesto que el ciclo económico es efecto provocado por quienes deliberadamente desean reducir el interés y dar paso a artificiosos auges.

Actualmente cualquier medida orientada a reducir el interés es juzgada por la gente como altamente recomendable y acertada, estimándose que el mejor método para conseguir tal reducción es el método de la expansión crediticia. De ahí la oposición a un patrón moneda sana. Los grupos de presión y los partidos políticos se muestran favorables a la política del dinero abundante y barato ${ }^{1}$.

1 La banca, mientras no cree nuevos medios de pago (emitiendo dinero bancario o abriendo nuevos créditos), jamás puede provocar la euforia alcista, aunque reduzca el interés a una tasa inferior a aquel interés que señalaría el mercado. En tal caso, estaría haciendo un regalo a sus prestatarios. Quienes desean evitar la euforia alcista para no padecer su inevitable secuela, la depresión, deben deducir de la 


\section{Pensamiento Crítico Vol. 19. N I}

Mediante la expansión crediticia se busca perjudicar a unos en beneficio de otros. Tal resultado es el mejor que puede provocar el intervencionismo monetario y crediticio, ya que no es raro que las medidas intervencionistas dañen a todos sin favorecer a nadie. $\mathrm{El}$ intervencionismo monetario y crediticio empobrece a la gente, pero eso no quiere decir que determinados grupos no pueden prosperar a su amparo. Quienes hayan de encontrarse entre los perdedores y quienes hayan de encontrarse entre los ganadores depende de las específicas circunstancias de cada caso.

El deseo de orientar los nuevos préstamos, de tal manera que con las supuestas ganancias de la expansión crediticia se lucren tan solo específicos grupos, impidiéndose a otros grupos cosechar las ganancias, ha dado origen al "control cualitativo del crédito". Esas nuevas facilidades crediticias no deben emplearse en la Bolsa de Valores, haciendo subir las cotizaciones. Por el contrario, tales créditos deben ir a nutrir las "legítimas" actividades comerciales, las industrias manufactureras, la minería, la pesca, el comercio "sano" y la agricultura. Hay partidarios del control cualitativo del crédito que desearían evitar la inmovilización del nuevo dinero en capitales fijos; quisieran que se destinara a activos líquidos. Los gobernantes deben ordenar a la banca qué préstamos ha de conceder y qué préstamos ha de denegar.

Sin embargo, esas órdenes y prevenciones son inútiles. Esa discriminación entre los potenciales prestatarios nunca puede ser equivalente a la efectiva restricción de la expansión crediticia, único medio que: impide el alza de las cotizaciones bursátiles y obstaculiza nuevas inversiones en capital fijo. Porque es de importancia secundaria cuál es el camino que seguirán los nuevos préstamos en su acceso al mercado. Lo decisivo es que el mercado recibe el impacto del nuevo dinero: sí la banca amplía los préstamos a los agricultores, estos pueden pagar sus deudas, pagar sus compras al contado. Si la industria recibe dinero fresco para destinarlo a capital circulante, se halla automáticamente en situación de aplicar a distintos cometidos las sumas antes destinadas a capital circulante. En cualquier caso, se incrementan las disponibilidades líquidas, que sus poseedores destinarán a cualesquiera inversiones consideradas de mayor rentabilidad. Pronto tal dinero aparecerá en la Bolsa de Valores o se materializará en capitales fijos.

teoría del ciclo monetario que el que la banca rebaje o no el interés carece de trascendencia lo importante es que no haga expansión crediticia. Al comienzo, la expansión crediticia impone una transitoria rebaja del interés, pero esto no afecta al problema que nos ocupa. 


\section{Pablo Rivas Santos}

Antes $^{2}$, una circunstancia en toda expansión crediticia, determinaba la evaluación de los acontecimientos: no existía (sobre la expansión crediticia) acción concertada entre los distintos países y sus respectivos BCR.

Esa circunstancia daba lugar a que nunca fuera cuantitativamente uniforme la expansión crediticia de los diversos países: unos países hacían más inflación que otros países, lo que de inmediato se traducía en grave amenaza para sus reservas de divisas que fugaban hacia esos otros países. Por ello, sus BCR se veían obligados a imponer una drástica política restrictiva en la concesión de créditos. Así, se desataba la desconfianza y comenzaba la depresión. Sin embargo, el pánico pronto saltaba hacia esos otros países. Cundía el pánico entre los empresarios de esos otros países, quienes incrementaban su demanda de créditos, en el deseo de mejorar su liquidez para poder enfrentar cualquier contingencia. Esa creciente demanda crediticia alarmaba aún más a los Gobiernos de esos otros países, ya inquietos por las crisis iniciada en esos primeros países, lo que les haría recurrir a su vez a la restricción de crédito. En pocos días o semanas, la crisis era de alcance mundial.

Hoy en día, el que los BCR puedan (en esa circunstancia) decretar la devaluación de la moneda ha venido a modificar (hasta cierto punto) esa concatenación de acontecimientos. El BCR, al verse amenazado por la fuga de sus reservas hacia el exterior, en vez de restringir créditos o elevar la tasa del interés de los préstamos devalúa. Sin embargo, esa medida no resuelve el problema. Si al BCR no inquieta el alza de las monedas extranjeras, durante algún tiempo podría continuar su política de expansión crediticia. Pero, un día, la euforia se interrumpirá, hundiéndose el sistema monetario. Por eso, si los gobiernos no desean verse forzados a devaluar a un ritmo cada vez más acelerado, les resulta obligado evitar que su expansión crediticia supere la expansión que practiquen aquellos países con quienes desean mantener equilibrado el cambio exterior.

Muchos economistas piensan que cuantas veces los BCR desencadenen la expansión crediticia se sucederán (con regular alternativa) los períodos de auge y depresión. Consideran que la expansión crediticia (en el futuro) provocará efectos

2 Antiguamente, otra circunstancia en toda expansión crediticia determinaba la evaluación de los acontecimientos : la expansión crediticia se producía bajo el patrón moneda sana. Esta primera circunstancia obligaba al BCR a mantener la convertibilidad de la moneda nacional a cierta paridad fija. 


\section{Pensamiento Crítico Vol. 19. N I}

similares a los de las crisis financieras de los 70, 80, las crisis mexicana, asiática, rusa y brasileña de los 90 y las crisis financieras del 2008 y 2009. Sin embargo, cabe dudar de que las circunstancias hoy concurrentes sean las circunstancias de antes. La teoría del ciclo económico es tan conocida, que aquel inocente optimismo que animaba al empresario durante los períodos de auge, ha dado paso a desconfiado escepticismo. No sería extraño que, en el futuro, variara la reacción del mundo empresarial ante la expansión crediticia. Posiblemente los empresarios ya se hayan dado cuenta de que la expansión crediticia tiene siempre el mismo final $\mathrm{y}$, consecuentemente, cabe que renuncien a ampliar sus operaciones durante las épocas de dinero fácil. Hay síntomas que aparecen anunciar el cambio. Sin embargo, sería prematuro deducir conclusiones definitivas.

En cierto aspecto, la teoría monetaria de los ciclos económicos ha tenido influencia sobre la marcha de los acontecimientos. Hay 2 conclusiones de esta teoría: que la causa originaria de la crisis es el previo auge; y que este previo auge es, a su vez, efecto de la anterior expansión crediticia. Por eso se generaliza la alarma tan pronto como aparecen los primeros síntomas. Incluso los BCR comienzan enseguida a hablar de la conveniencia de impedir nuevas subidas de precios y de reducir los márgenes de beneficios, imponiendo efectiva restricción del crédito. Así se degüella rápidamente el auge y comienza la recesión. Tal es la razón por la que los ciclos económicos se hayan hecho mucho más cortos. Hemos tenido a lo largo de tal período auges y depresiones ; pero sus respectivas fases han sido de corta duración, sucediéndose las unas a las otras con una mayor frecuencia. Como el auge termina antes, hay menos malas inversiones $y$, en consecuencia, la subsiguiente depresión es también de menor gravedad.

\section{Algunos conceptos fundamentales sobre los que se basa el control cam- biario y el comercio bilateral en Venezuela y Argentina}

En cuanto el Gobierno pretende dar a la moneda nacional (con respecto a las monedas extranjeras) un valor superior al valor que le reconoce el mercado, es decir, en cuanto el Gobierno fija a las monedas extranjeras tasas máximas inferiores a su precio de mercado, se producen las consecuencias previstas por la ley de Gresham. Aparece lo que indebidamente el Estado denomina escasez de monedas extranjeras. 


\section{Pablo Rivas Santos}

El dinero es un activo luego por fuerza tiene que ser escaso ${ }^{3}$. Cuando el Estado se lamenta de la escasez de monedas extranjeras, se lamenta del efecto provocado por su política de control cambiario. Al tipo de cambio oficial arbitrariamente señalado, la demanda excede a la oferta. Si el Estado, tras reducir (mediante la inflación) el poder adquisitivo del dinero en relación con las monedas extranjeras; se abstuviera de interferir los cambios extranjeros; nunca aparecería esa escasez de monedas extranjeras, a la que el Estado alude. Quien estuviera dispuesto a pagar el correspondiente precio de mercado hallaría todas las monedas extranjeras que deseara.

Sin embargo, el Estado quiere evitar el alza de la moneda extranjera y, confiado en el poder de los tribunales y la policía, prohíbe cualquier transacción que no concuerde con el precio oficial.

El Estado dice que el alza de la moneda extranjera es consecuencia de una desfavorable balanza de pagos aprovechada por los especuladores para lucrar personalmente. En el deseo de remediar esa situación se adoptan medidas orientadas a restringir la demanda de monedas extranjeras. Solo quienes vayan a destinar las monedas extranjeras a operaciones previamente aprobadas por el Estado podrán adquirir esas monedas extranjeras en lo sucesivo. Aquellos bienes que el Estado considere superfluo dejarán de importarse. Se evitará, en la medida de lo posible, el pago del principal e intereses de la deuda externa. Se restringen los viajes al extranjero. Sin embargo, el Estado no se da cuenta de que con tales medidas jamás puede mejorar la balanza de pagos. Reducidas las importaciones, las exportaciones paralelamente disminuyen: ino porque se impida a la gente comprar bienes extranjeros, pagar créditos internacionales y viajar al extranjero, esa gente va a atesorar el correspondiente efectivo! Al contrario, incrementarán sus compras de bienes de consumo y de factores de producción en el interior del país, desatando así una tendencia alcista en los precios. Y cuanto más suban estos precios, menos se exportará.

El Estado, ante esa realidad, cree en el caso de proseguir por el camino de la injerencia y estatiza el comercio exterior. Todo aquel que reciba monedas extranjeras -procedentes de exportaciones- habrá de cederlas al Estado al precio oficialmente fijado. Si el mandato del Estado -que equivale a gravar la exportación- es rigurosamente

3 Todo bien económico es escaso; las disponibilidades de todo bien económico son insuficientes para atender cuantos usos útilmente cabría dar al bien económico. 


\section{Pensamiento Crítico Vol. 19. N I}

acatado, las exportaciones se reducen, pudiendo incluso cesar por completo. Esto repugna al Estado. Sin embargo, tercamente se resiste a reconocer que su injerencia está fallando cada vez más, habiendo sido provocada una situación que es mucho peor que aquella situación que deseaba corregir. Entonces, el Estado monta nuevo mecanismo artificioso. Procede a subvencionar las exportaciones en la medida necesaria para compensar las pérdidas que les ocasiona a los exportadores esa implantada política de control cambiario.

El BCR, que controla la compraventa de monedas extranjeras; por su lado, aferrándose tercamente a la ficción ( de que los tipos de cambio en realidad no se han elevado y que la paridad oficialmente establecida es la paridad efectiva), facilita monedas extranjeras a los importadores al precio oficial. Ello supone premiar las importaciones. Todo importador que consigue monedas extranjeras, obtiene señalados beneficios al vender en el interior del país los bienes importados. Por ello, el Estado recurre a nuevas arbitrariedades. O eleva los aranceles o impone cargas y gravámenes a las importaciones; encarece por un procedimiento u otro, la compra de monedas extranjeras.

Así comienza a funcionar el control cambiario. Sin embargo, el control cambiario solo opera porque se están acatando las cotizaciones del mercado libre de monedas extranjeras : el exportador obtiene por las monedas extranjeras que entrega al Estado su equivalente oficial, además del correspondiente subsidio; con lo que acaba por cobrar una suma igual al cambio del mercado libre. El importador a su vez paga por la moneda extranjera el precio oficial y una prima, tasa o impuesto especial ; de tal manera que desembolsa el cambio de mercado libre. En esta situación, la heterodoxia que no acierta a percatarse de la realidad son aquellos economistas que elogian : las nuevas experiencias y el método del intervencionismo monetario.

Monopolizar el comercio de las monedas extranjeras concede al Estado el control del comercio exterior. Sin embargo, no por ello el Gobierno logrará influir las cotizaciones extranjeras. Es inútil que el Estado prohíba la publicación de los cambios reales. En tanto haya comercio exterior, solo las cotizaciones libres y efectivas serán tomadas en cuenta por quienes operen en el mercado. 


\section{Pablo Rivas Santos}

\section{Conclusiones}

El Estado, a fin de ocultar la realidad, quisiera que la gente eludiera el mencionar los verdaderos tipos de cambio manejados. Procura organizar el comercio exterior a base de trueque, evitando así las expresiones monetarias. Se montan los tratados comerciales bilaterales. Cada parte se compromete a entregar determinada cantidad de bienes, recibiendo en pago otra "serie de bienes. En tales convenios se rehúye, con sumo cuidado, toda alusión al dinero y a los cambios. Sin embargo, los países contratantes en su mercado interno calculan el valor de lo que compran y venden en base a los precios internacionales en monedas extranjeras. Mediante estos conciertos de trueque y compensación el comercio bilateral sustituye el comercio multilateral. Lo que no se consigue con ello es reducir la pérdida del poder adquisitivo experimentado por la moneda nacional con respecto a las monedas extranjeras y bienes.

El control cambiario es un nuevo paso por el camino que conduce a la implantación del populismo. Su ineficacia es notoria. Ni a la corta ni a la larga, en lo más mínimo influye en la determinación del precio de las monedas extranjeras.

\section{Referencias bibliográficas}

FRIEDMAN, Milton. (1960). POLÍTICAS MONETARIAS DE ESTABILIZACIÓN. ARGENTINA. Editorial Ateneo. Pag. 310-350.

FRIEDMAN, Milton. (1980). MONEDA Y DESARROLLO. ESPAÑA. Editorial Ateneo. Pag. 123-152.

FRIEDMAN, Milton. (1971). NUEVA REFORMULACIÓN DE LA TEORÍA CUANTITATIVA DEL DINERO. ESPAÑA. Editorial Continental. Primera Edición. Pag. 123-152.

LUCAS, Robert. (1987). TEORÍA DE LOS CICLOS ECONÓMICOS. ESPAÑA. Alianza editorial. Pag. 113-152.

MUNDELL, Robert A. (1971). TEORÍA MONETARIA. ESPAÑA. Ediciones Amorrurtu Editores. Pag. 323-430. 


\section{Pensamiento Crítico Vol. 19. No I}

VON HAYEK, Friedrich. (1978). DESNACIONALIZACIÓN DEL DINERO. ESPAÑA. Editorial Continental. Pag. 143-187.

VON MISES, Ludwig. (1966).TEORÍA DE LA MONEDA Y EL CRÉDITO. ESPAÑA. Fundación Ignacio Villalonga. Pag. 239-452.

VON MISES, Ludwig. (1980).ACCIÓN HUMANA. ESPAÑA. Fundación Ignacio Villalonga. Pag. 180-332. 